\title{
ReSt Module Using a Four-Steps Approach Based on Case Study Example and Infographic for SPPS Novice Users: Design and Development
}

\author{
Azura Ishak ${ }^{1 *}$, Hazura Mohamed ${ }^{1}$ and Rosseni $\operatorname{Din}^{2}$ \\ ${ }^{1}$ Faculty of Information Science and Technology Universiti Kebangsaan Malaysia, 43600 UKM \\ Bangi, Selangor, Malaysia \\ ${ }^{2}$ Faculty of Education Universiti Kebangsaan Malaysia, 43600 UKM Bangi, Selangor, Malaysia
}

\begin{abstract}
Using software packages to analyse quantitative data, such as SPSS, appears to be challenging amidst unskilled novice users. Studies have shown that example-based learning is an easy-to-understand method for novice, while infographic display is an effective strategy to aid the learning processes. As a result, a module with four-step approach based on case study examples and infographic called 'ReSt' (Research and Statistics) was developed, mainly to assist novice users in analysing quantitative data using SPSS within the actual research context. The ADWa model (amalgamation of ADDIE and Waterfall Model) was incorporated as an instructional design model for the ReSt module. The four-step approach is an innovation that depicts the flow of research process. The example-based learning was integrated into ReSt module to facilitate users in relevant information-seeking processes and to help them to concentrate on studying the problem-solving steps provided. The display of infographic information allows difficult information to be processed in a simple form to enhance the learning process. In fact, the cognitive load theory is the main foundation of the ReSt module design. It is hoped that the ReSt module would be able to serve its purpose in guiding novice users to learn quantitative data analysis using SPSS by enhancing their skills.
\end{abstract}

Keywords: PSS; novice; cognitive load theory; example-based learning; infographic

\section{INTRODUCTION}

SPSS refers to one of the most widely and commonly used software packages for quantitative data analyses (Connolly, 2007; Archee \& Gurney, 2006). In order to accurately analyse quantitative data using the SPSS, its users should be able to comprehend the complete research process. Students should always be exposed and reminded that the primary purpose of data analysis is to address the research question outlined in the study (Blankenship,2010). The impact of erroneous data analyses leads to invalid survey outcomes. The inability to perform an analysis correctly can negatively affect the research quality (Mohd. M. A. et. al., 2016).

Statistical analysis for a quantitative study is often perceived to be the most difficult step by a novice researcher (Yin et. al., 2006) Novices refer to those inexperienced or with limited knowledge regarding situational characteristics of their domain (Ross et. al., 2005). Thus, the SPSS reference material is highly sought by novice users to guide them in overcoming the abovementioned errors. Nonetheless, the existing references to quantitative analysis and statistical data are frightening to many users and SPSS reference materials should be more easily understood (Connoly, 2007). Some SPSS references are too brief and give insufficient information regarding data analyses (List, 2007).

Moreover, based on the early feedback from SPSS novice users, conclude that the existing reference material such as

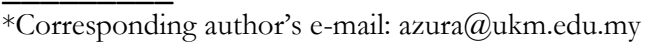


modules are insufficiently interesting to promote SPSS learning and does not support on students' cognitive ability. Hence, the purpose of this study is to present the design and development of a module which aids in the learning of SPSS data analysis for novice users. The module would be able to appear to be an interesting instructional module for SPSS novice users as the presentation of information is displayed in a simple and easy-to-understand manner.

\section{MATERIALS AND METHODS}

ReSt refers to the abbreviation of 'Research and Statistics' and it is an instructional learning module in Malay version for quantitative data analysis using SPSS realistically and practically within the actual world research context for novice users. The design and development of ReSt module to serve as a guide for SPSS data analysis are based on two instructional design models; ADDIE and Waterfall.

The combined model is called ADWa model beginning with analysis, design, development and testing, and the last phase is implementation and evaluation as presented in Figure 1. The simplified ADWa model is adapted to ReSt module due to time and cost constraints which are suitable for small development project. Moreover, the two were combined due to their own strengths. ADDIE is a systematic model that can provide a framework guide to develop effective educational products or learning resources that are easy to follow (Branch, 2009), while the Waterfall model is easy to understand and use (Datyal,2015).

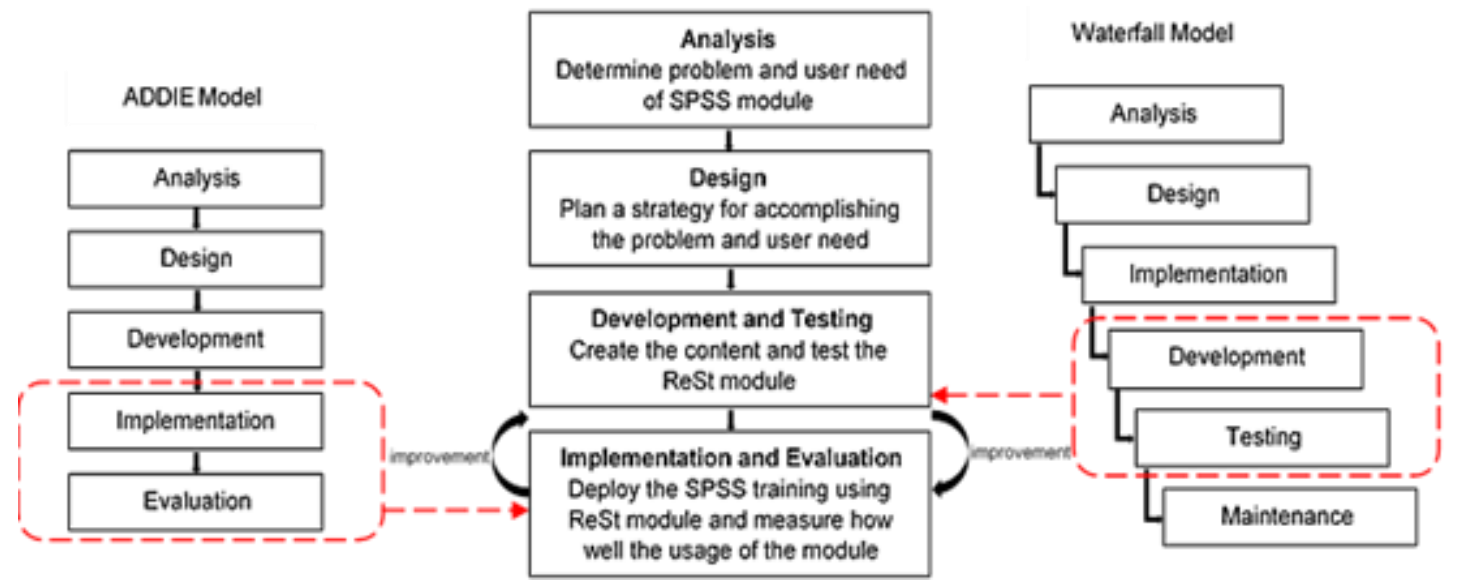

Figure 1. ADWa model

III. RESULTS AND DISCUSSIONS

\section{A. ReSt Module Framework}

The ReSt module is designed and developed based on theory of its basis and appropriate approach are able to meet the module objectives portrayed in the framework of Figure 2. The ReSt module integrates cognitive load theory, example-

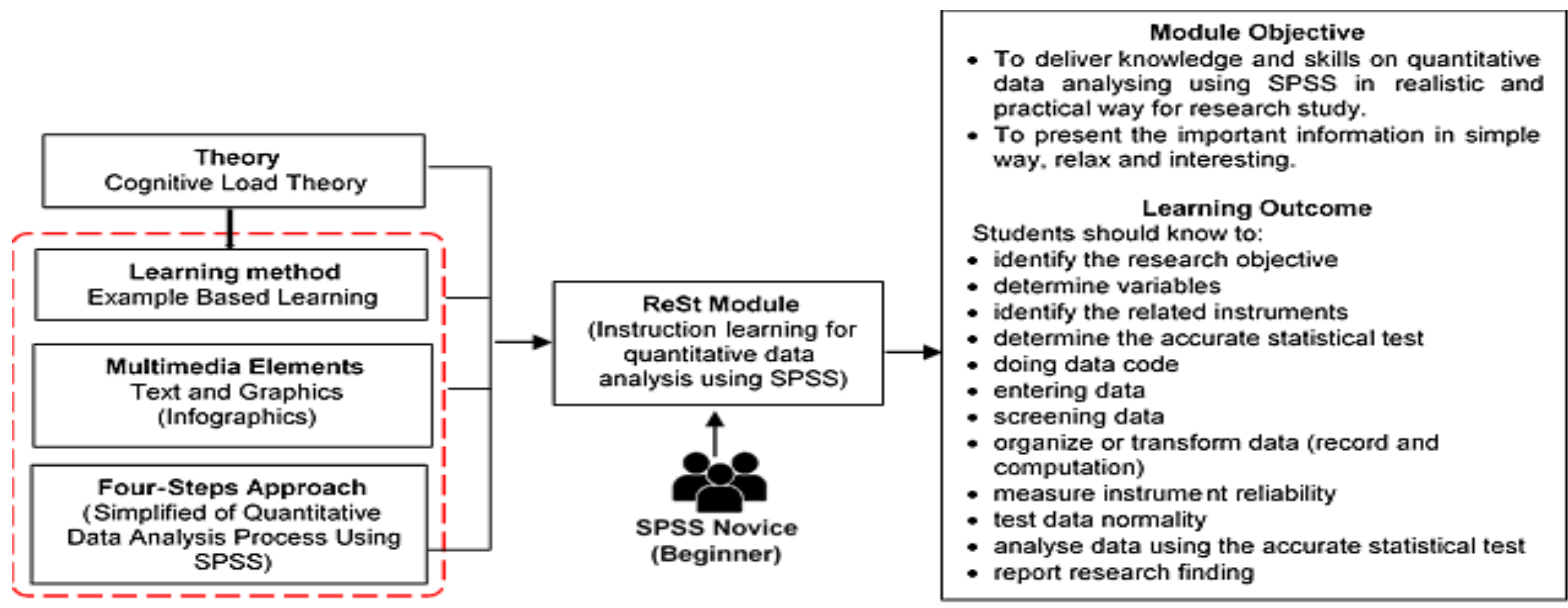

Figure 2. ReSt module framework 
based learning, infographics, and the intervention of fourstep approach which simplifies quantitative data analysis process via SPSS.

\section{Cognitive Load Theory}

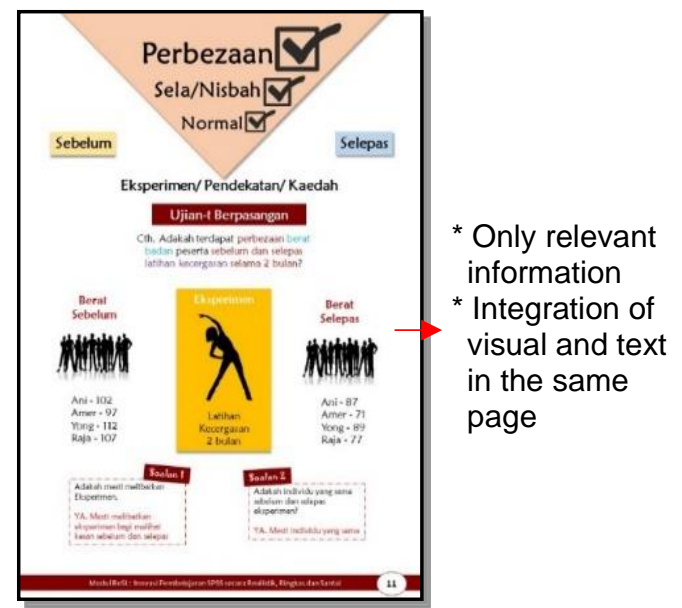

Figure 3. Implementation of cognitive load theory

Cognitive load theory is the basis of ReSt module development by adopting the cognitive ability of a novice user. The basic concept of the cognitive load theory is that since cognitive ability in work memory is limited and if the learning task requires much capacity, the learning process comes to a halt (De Jong, 2010). From the aspect of teaching design, learning takes place well if the information is based on the human cognitive ability (Sweller, 1988]. This means, the teaching materials for novice users should suit their cognitive ability for further comprehension. Based on this theory, teaching designs should contain information on the same page in the form of tables, charts, and pictures so that the students need not flip the pages back and forth to search for objects related to the explanation (Rosseni, 2009).

Thus, in order to reduce cognitive load, all relevant elements, such as texts and visual, have to be integrated simultaneously in accordance to the suitability of the information presented as illustrated in Figure 3.

\section{Example-Based Learning}

The ReSt module integrates the example-based learning to give exposure to students about analysing data in a realistic situation according to case study instances (see Figure 4). The example-based learning reflects a problem-solving model that consists of three components: problem statement, problem-solving, and final solution for the problem (Renkl \& Atkinson, 2003). The example-based learning approach helps students to find relevant information via problem-solving steps to build problemsolving schemes (Wittwer \& Renkl, 2010) in no time (Kalyuga, 2003).

In the learning process, the level of knowledge the students possess should be taken into account as it is a crucial factor in determining the suitability and need of the information to the targeted users (Rikers, 2006). For users with no prior knowledge of a domain, such as novice users, they need to be fully supervised especially during the initial phase of learning (Van Gog, 2004).

Thus, easy-to-understand learning materials should be embedded as references and irrelevant information must be discarded to avoid cognitive loads amongst novice users. The example-based learning is suitable for novice users (Paas, 2003; Jalani et. al., 2013] as this method can
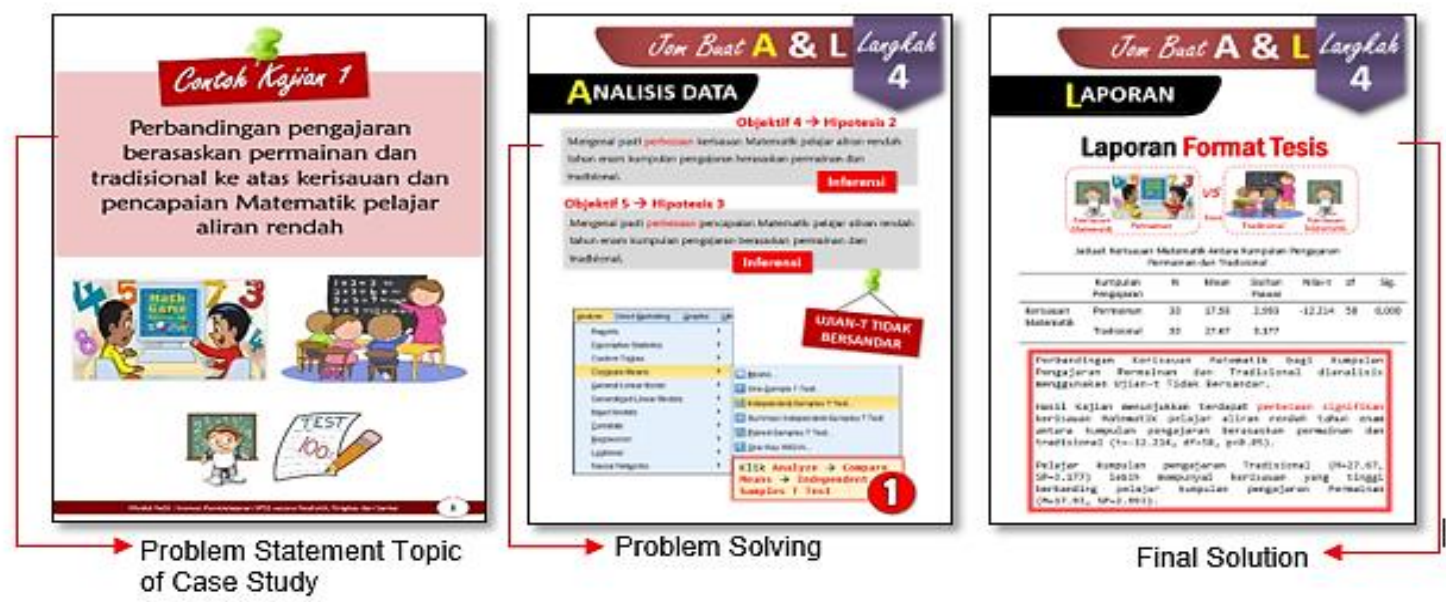

Figure 4. Example-based learning through case study example 
eliminate ineffective external cognitive load during the learning process (Sweller, 1988; Van Merrienboer \& Sweller, 2005).

\section{Infographics}

The presentation of ReSt module is based on infographics; fewer texts, but more visuals to stimulate learning in an attractive manner (see Figure 5). Infographics consist of many visual components, such as pictures, drawings, diagrams, symbols, graphics, and texts, which can be used separately or merged for the purpose of conveying information. Innovations brought through infographics are the use of visual components to deliver information and have a unique way of building content (Dick, 2014).

The infographic features as visual description enhances

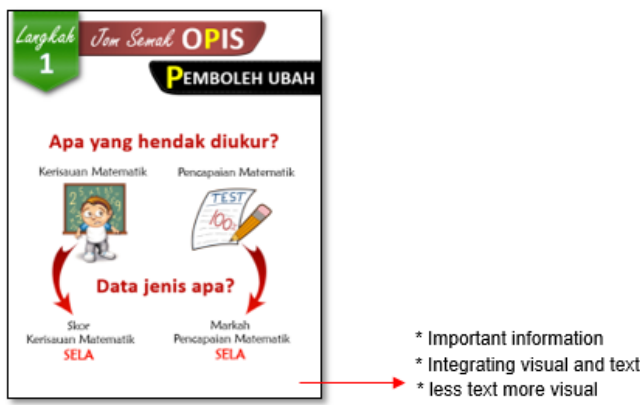

Figure 5. Infographic presentation

students' understanding and eases information search; graphic representation that combines appropriate words and pictures; self-explanatory that does not require further explanation; makes the understanding process quick and consistent; focuses on vital clues, and excites the readers (El-Arabi, 2008).

Infographics facilitate learning and may be used for the purpose of teaching fundamental information of a course, to convey new information or to verify the existing information (Serkan, 2016). Infographics make it easy for learners to understand something that has already been arranged and become the foundation to form the scheme required to be fostered into one's mind.

The infographics supply processes and steps, such as using the existing information, learning new information, and presenting the information in an organized manner. In fact, infographics can help learners to improve their critical thinking skills apart from analysing and fostering their synthetic skills (Mol, 2011; Hart, 2013).

\section{The Four-Step Approach}

The four-step approach is based on the flow of research process reveals that the main need of most learners in learning SPSS was to assist in analysing their own research data. Hence, the four-step approach which consists of 'JomSemak OPIS', 'JomBuatKoMTO', 'JomUjiKeK', and 'JomBuat A\&L', are employed to guide the students to analyse data using SPSS step-by-step based on accurate quantitative data analysis process (see Table 1).

Table 1. The four-step approach

\begin{tabular}{ll}
\hline Steps & Description \\
\hline Step 1: 'JomSemak & • Objective (Objektif) \\
OPIS' & • Variables (Pemboleh Ubah) \\
(Designing study) & - Instruments (Instrumen) \\
& - Statistical Test (Ujian \\
&
\end{tabular}

\section{Step 2: \\ 'JomBuatKoMTO'}

(Preparing data)

\section{Step 3: 'JomUjiKeK'}

(Test of data

normality and

measurement tool)

Step 4: 'JomBuat A\& $\mathbf{L}^{\prime}$

(Analysing data and report)

\section{Statistik)}

- Data Code (Kod Data)

- Data Entering (Masuk Data)

- Data Screening (Tapis Data)

- Data Organization (Organisasi Data)

- Instrument Reliability (Kebolehpercayaan Instrumen)

- Data Normality (Kenormalan Data)

- Data Analyzing (Analisis Data)

- Report Finding (Laporan Hasil Kajian)
The four-step approach refers to a systematic guide that facilitates the learning of data analysis using SPSS within the context of comprehensive research that ranges from the beginning, identifying research objective until finally, making a review report based on the thesis format. The use of acronyms is a strategy used to better facilitate the novice students in remembering the data analysis process using SPSS accurately. The implementation of this four-step 
approach is also supported by the disclosure of case study instances that are synonymous with the real world of researches. The four-step-approach with the selected case study examples has been validated by two statistician expert and tested among five novice users help them to understand and to learn data analysis via investigation mode.

\section{B. Parts in ReSt Module}

The module is comprised of four series; starting from module one that covers the basic concept of research process and followed by case study example one until three in each of modules two, three, and four (see Table 2). Module one provides exposure on the basic processes of research and the fundamental statistical concepts. The purpose is to ensure that the users are clear about the basic concepts of research and statistics, as these two components must be understood prior to learning data analysis in more detail using the SPSS in modules two until four.

Module two guides and depicts skills about the basic inferential analysis using Pearson correlation and independent t-test, ANOVA and simple linear regression in module three, and paired t-test and independent chisquare in module four. All the modules are based on case study examples and cover descriptive analysis.

Table 2. Parts in ReSt module

\begin{tabular}{ll}
\hline Series & Content \\
\hline Module 1: Statistics & $\bullet$ Research Process \\
and Research & Important of \\
& identifying \\
& research process \\
& before analysing \\
& data using SPSS
\end{tabular}

$\begin{array}{ll}\text { Module 2: Case Study } & \text { - Descriptive } \\ \text { Example 1 } & \text { - Pearson } \\ \text { Comparison game and } & \text { correlation } \\ \text { traditional based teaching } & \text { - Independent t-test } \\ \text { on Mathematics anxiety } & \\ \text { and achievement } & \end{array}$

\begin{tabular}{ll}
\hline Module 3: Case Study & • Descriptive \\
Example 2 & • ANOVA \\
Stress and job satisfaction & • Simple Linear \\
among government, & Regression \\
private sector and self- & \\
employed wokers & \\
Module 4: Case Study & • Descriptive \\
Example 3 & - Paired t-test \\
The effect of physical & - Independent Chi- \\
fitness on body weight & Square \\
\hline
\end{tabular}

\section{SUMMARY}

The ReSt module is a basic reference material pertaining to SPSS to help novice users analyse quantitative data using SPSS based on correct procedure in a simple and attractive form. Starting with novice users' issues in analysing data, early feedback, and user needs; this module is built on the application of theory, model, learning methods, and appropriate multimedia elements. In comparison to other existing SPSS modules, this particular module applies the four-step approach based on case studies and infographics.

Besides, this module is designed and developed in accordance to novice-level cognitive ability, hence eases data analyses using SPSS. This module also has been tested by experts and novice users and has been improved based on their feedback before released in actual use. It is hoped that the ReSt module is not only easy to understand, but the integration of infographics display has successfully drawn users' attention to continuously explore the quantitative data analysis skills using SPSS in realistic and practical ways.

On top of that, this ReSt module would be able to help novice users to minimize errors in data analysis, which may mislead the study, thus ascertaining its relevancy and appropriateness as a reference in learning data analysis with SPSS. It is expected that the use of ReSt module would serve its purpose in guiding novice users to learn quantitative data analysis using SPSS and highly beneficial for novice users as the module design weighed in the novice level cognitive ability.

Hence, to prove the effectiveness of the ReSt module in actual use, the survey focuses on the impact of the usability and perceived quantitative data analysis skills using SPSS among novice users will be done for further research. 


\section{ACKNOWLEDGEMENTS}

The authors wish to acknowledge the support from Faculty of Information Science and Technology, Faculty of Education and Centre for Collaborative Innovation, National University of Malaysia.

\section{REFERENCES}

Archee, R, \& Gurney, M 2006, 'Flash me now: using blended learning to teach SPSS to undergrads', Proceedings: IADIS Virtual Multi Conference on Computer Science and Information Systems (MCCSIS 2006),15th-19th May 2006. Blankenship, D 2010, Applied research and evaluation methods in recreation, Human Kinetics, United States.

Branch, RM 2009, Instructional design-the ADDIE approach, Springer, New York, US.

Connolly, P. 2007, Quantitative data analysis in education: a critical introduction using SPSS, Routledge, London, UK.

Datyal, D 2015, 'Proposed model to overcome the problems in waterfall model', International Journal of Computer Science and Information Technologies, vol. 2. No. 2, pp. 29-32.

De Jong, T 2010, 'Cognitive load theory, educational research, and instructional design: some food for thought', Instructional Science, vol. 38, no. 2, pp. 105-134.

Dick, M 2014, 'Interactive infographics and news values', Digital Journalism, vol. 2, no. 4, pp. 490-506.

El-Arabi, R 2008, Infographic design, viewed 18 Jun 2018, <https://kenanaonline.com/files/oo11/11257/ GraphicDesign.pdf>.

Hart, G 2013, Effective infographics: telling stories in the technical communication context, viewed 3 November 2018, <http://techwhirl.com/effective-infographicstelling-stories-in-the-technical-communication-context/>

Jalani, NH, Lai, CS, Aziz, A \&Samad, N 2013, 'Kesanpembelajaranberasaskanmasalah, contoh, dan contoh-masalah terhadap pemerolehan pengetahuan, prestasi pemindahan dan pelaburan usaha mental pelajar teknologi elektrik', National Conference on Engineering Technology (NCET),1st-2th July 2013, Setia Alam, Selangor.
Kalyuga, S, Ayres, P, Chandler, P \& Sweller, J 2003, 'The expertise reversal effect', Educational Psychologist, vol. 38, no. 1, pp. 23-31.

List, Dennis 2007, Know your audience: a practical guide to

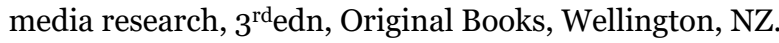

Mohd. Mahzan Awang, Abdul Razaq Ahmad \& Faridah Mydin Kutty, 2016. 'Tahap kemahiran pelajar pascasiswazah dalam penyelidikan Pendidikan dan sains sosial', in Inovasi dalam pengajaran dan pembelajaran: kajian kes IPT di Malaysia, UKM, Bangi, pp. 25-36.

Mol, L 2011, 'The potential role for infographics in science communication', Master thesis, Vrije University Amsterdam, Netherlands.

Paas, F, Renkl A, \& Sweller, J 2003. 'Cognitive load theory and instructional design: recent developments', Educational Psychologist, vol. 38, no. 1, pp. 1-4.

Renkl, A, \& Atkinson, RK 2003, 'Structuring the transition from example study to problem solving in cognitive skill acquisition: a cognitive load respective', Educational Psychologist, vol. 38, no. 1, pp. 15-22.

Rikers, R M 2006, 'A critical reflection on emerging topics in cognitive load research', Applied Cognitive Psychology, vol. 20, pp. 359-364.

Ross, KG, Phillips, JK, Klein, G \& Cohn, J 2005. Creating expertise: a framework to guide technology-based training, Final Technical Report for the Marine Corps Systems Com mand/Program Manager for Training Systems, Klein Associates, Fairborn, OH.

Rosseni Din 2009, Manuskrip prinsip asas kejurulatihan komputer, Universiti Kebangsaan Malaysia, Bangi.

Serkan, Y 2016, 'Infographics for educational purposes: their structure, properties and reader approaches', The Turkish Online Journal of Educational Technology, vol. 15, no. 3 , pp. 98-110. 
Sweller, J. 1988. Cognitive load during problem solving: effects on learning. Cognitive Science 12(2): 257-285.

Van Gog, T, Paas, F \& Van Merriënboer, JJG 2004, 'Processoriented worked examples: Improving transfer performance through enhanced understanding', Instructional Science, vol. 32, pp. 83-98.

Van Merrienboer, JJG \& Sweller, J 2005, 'Cognitive load theory and complex learning: Recent developments and future directions, Educational Psychology Review, vol 17, pp. 147-177.

Wittwer, J \& Renkl, A 2010, 'How effective are instructional explanations in example-based learning? Ameta-analytic review', Educational Psychology Review, vol. 22, no. 4, pp. $393-409$.

Yin, LK, Lieng, TC \& Cheong, WK 2006, 'Research notes how to analyse your research data? Illustrations with hands-on exercises using SPSS', Online, vol. 1, no. 2, pp. 77-81. 